УДК 621.373.826, 621.9.048.7

\author{
Ю.Н. Кульчин, А.И. Никитин, Е.П. Субботин \\ Институт автоматики и процессов управления \\ Дальневосточного отделения РАН, г. Владивосток, Россия
}

\title{
ЛАЗЕРНАЯ ПОДВОДНАЯ ОЧИСТКА КОРПУСОВ МОРСКИХ СУДОВ
}

\begin{abstract}
Рассмотрена возможность применения лазерного излучения для очистки корпусов судов от биологического обрастания непосредственно в морской среде без докования. На основании результатов исследования оптических параметров морских биообрастателей, красок, используемых для защиты поверхностей корпусов морских объектов, и наиболее распространенных материалов, используемых для конструирования корпусов судов, разработан и экспериментально обоснован метод лазерной подводной очистки поверхностей от биообрастателей. Представленные в статье технологические решения использованы для создания макета аппарата лазерной подводной очистки поверхности объектов от биообрастателей.
\end{abstract}

Ключевые слова: лазерная подводная очистка, биообрастание, подводный телеуправляемый необитаемый аппарат.

\author{
Yu.N. Kulchin, A.I. Nikitin, E.P. Subbotin \\ Institute of Automation and Control Processes \\ Far Eastern Branch of the RAS, Vladivostok, Russia \\ LASER UNDERWATER CLEANING OF HULLS \\ OF SEA VESSELS
}

The article discusses the possibility of using the energy of laser radiation to clean the hulls of ships from biological growth directly in the marine environment without docking.

Based on the results of the study of the optical parameters of marine biofouling agents, paints used to protect the surfaces of the hulls of marine objects and the most common materials used to design the hulls of ships, a method of laser underwater cleaning of surfaces from biofouling agents was developed and experimentally substantiated. The technological solutions presented in the article were used to create a "model of the apparatus for laser underwater cleaning of the surface of objects from biofouling".

Keywords: laser underwater cleaning, biofouling, remotely operated underwater vehicle.

\section{Введение}

Эффективная и безопасная эксплуатация морского судна определяется множеством факторов, влияющих на его технические характеристики, регламентированные международными требованиями, нормами и правилами безопасности жизнедеятельности на море. Обязательное периодическое освидетельствование подводной части судов является эффективным инструментом для оценки технического со- 
стояния подводной части корпуса, отверстий, донно-бортовой арматуры, наружных частей рулевых устройств, пропульсивной установки и навигационного оборудования. Как правило, такая процедура проводится при нахождении судна в доке с интервалом в 36 месяцев. В случаях интенсивной эксплуатации судов дальнего плавания в тропических водах мирового океана процесс биообрастания корпуса и его элементов происходит довольно быстро и отрицательно влияет на гидродинамические характеристики, что приводит к ухудшению ходовых качеств судна, снижению скорости, увеличению эксплуатационных затрат. На борьбу с проблемой морского обрастания, учитывая ее масштаб, в мире ежегодно тратятся огромные средства [1].

Существующие технологии подводной механической очистки корпусов судов на плаву - трудоемкие процедуры, часто приводящие к повреждению защитного покрытия корпуса, кроме того, участие человека в легководолазном снаряжении исключает оперативное использование этой технологии в океане [2].

Научные исследования и разработки по вопросам, связанным с поиском оптимальных технических решений по подводной очистке морских судов на плаву, проводятся сравнительно давно как в нашей стране, так и за рубежом [2-5].

Зарубежные исследователи создали несколько образцов телеуправляемых необитаемых подводных аппаратов (ТНПА), способных выполнять технологическую операцию очистки корпуса судна на плаву от биологических обрастаний. Компаниями «ЕСАНytec», Франция, «GACEnvironHullLimited», ОАЭ, «SeaRobotics», США, разработаны ТНПА, выполняющие функции механической очистки обрастаний корпуса с использованием щеток, шарошек, вибрирующих ножей и т.д. Однако эффективность проведения таких работ связана с рядом недостатков: низкие величины восстановления технической скорости судов в большинстве случаев очистки, значительные повреждения защитных покрытий очистными средствами, длительность процесса выполнения данных работ и т.д.

Механизация, автоматизация и роботизация процессов оперативной очистки подводной части судна на плаву представляют собой современную научно-техническую задачу, направленную на достижение высокой производительности и удешевление этого производственного процесса. 
Целью настоящей статьи является представление результатов исследований метода оперативной лазерной очистки поверхности подводной части судов и гидротехнических сооружений от различных форм морских организмов-обрастателей.

Актуальность проведенной работы заключается в том, что ввиду крайней сложности поставленной задачи аналогов технологии оперативной лазерной очистки подводной части судов в открытом море от различных видов морских организмов-обрастателей как в России, так и за рубежом не существует.

\section{1. Поглощение оптического излучения биообрастателями, защитными материалами и металлами}

Процесс «лазерной очистки» подводной части поверхности корпусов морских объектов основан на взаимодействии лазерного пучка с биологическим материалом, в результате которого происходит разложение и/или абляция органического вещества и его последующее удаление с поверхности объекта. Механизм физико-химического взаимодействия лазерного излучения (ЛИ) с биологическими тканями основан на их способности поглощать определенные длины волн электромагнитного излучения на определенных длинах волн [6].

Существенное отличие технологии лазерной очистки подводной части поверхности корпусов морских объектов от обычной лазерной обработки/очистки заключается в том, что металл подводной части корпусов судов/кораблей и обеспечивающее оперативную защиту от биообрастания лакокрасочное покрытие (краска) либо не должны поглощать, либо поглощать незначительно лазерное излучение, используемое для удаления морских организмов-обрастателей, чтобы сохранить их целостность.

Это потребовало выполнения значительного объема предварительных исследований по измерению поглощения светового излучения морской водой, бологическими объектами и материалами, используемыми для защиты объектов от биообрастания, в диапазоне длин волн 200-1800 нм.

\section{1. Спектральное поглощение оптического излучения морской водой и биообрастстелями}

Естественной средой обитания биоты является морская вода. Морская вода, которая также присутствует в организмах биообрастателей, является сложной по химическому составу средой, имеющей 
собственные оптические характеристики и спектральное пропускание и поглощение. Для определения спектральных характеристик морской воды нами был использован специальный образец чистой морской воды, предоставленный Национальным научным центром морской биологии Дальневосточного отделения РАН. Результат измерений спектра поглощения морской воды представлен на рис. 1.

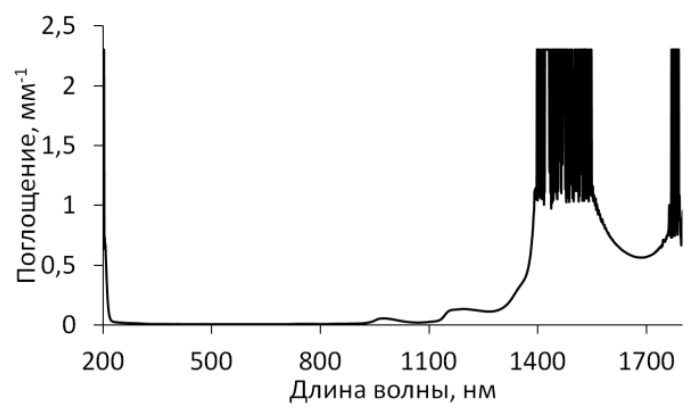

Рис. 1. Измеренный спектр поглощения оптического излучения для образца морской воды

Для изучения процесса поглощения светового излучения тканями биообрастателей нами использовались образцы наиболее активно участвующих в процессах биообрастания подводной части поверхности подвижных и стационарных морских объектов: водоросли, усоногие ракообразные (Balanus, Cirripedia), трубчатые черви (Polychaeta), мшанки, двустворчатые моллюски (Mytilussp.), личиночнохордовые (Ascidiae), гидроидные (Hydrozoa).

На рис. 2, а показан спектр поглощения для материала асцидии булавовидной. Как видно, поглощение излучения является наиболее значительным в диапазонах 200-620 и 1150-1800 нм. В диапазоне 700-1150 нм биологический материал обрастателя является практически прозрачным. Сравнение результатов на рис. 2 с результатами на рис. 1 свидетельствует о том, что сильное поглощение материала обрастателя в области длин волн более 1150 нм обусловлено наличием большого количества воды в биологических тканях.

Результат измерения спектра поглощения для материала гидроидного полипа (Obelialongissima, Hydrozoa) показан на рис. 2, б. Во многом полученный результат совпадает с результатом на рис. 2, $a$. Наблюдающееся отличие поглощения в диапазоне 1350-1500 нм, повидимому, связано с влиянием процесса поглощения морской воды и 
особенностями поглощения материала организма обрастателя. В спектральных областях 700-1350 и 1500-1800 нм значение коэффициента поглощения материала обрастателя было незначительным и находилось на уровне 1,1-2,0 о.е.

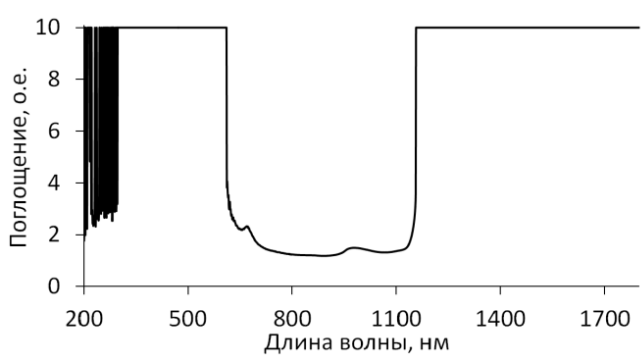

$a$

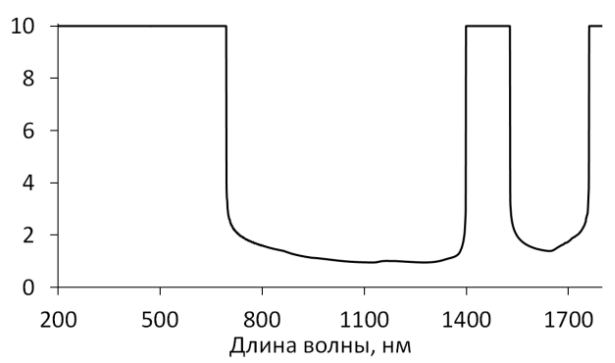

б

Рис. 2. Спектры поглощения оптического излучения для образцов асцидии булавовидной (Styelaclava) ( $a$ ) и гидроидного полипа

(Obelialongissima, Hydrozoa) (б)

На рис. 3 представлены спектры поглощения для мидии тихоокеанской (MytilusTrossulus, Mytilidae) и морского желудя (Balanusimprovisus, Cirripedia - усоногие раки).
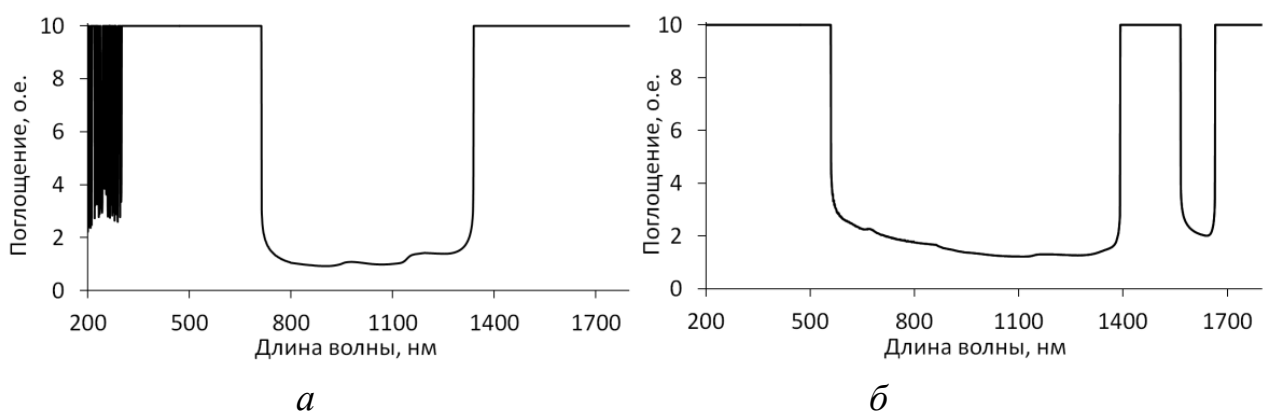

Рис. 3. Спектры поглощения оптического излучения: $a$ - для мидии тихоокеанской (MytilusTrossulus, Mytilidae) и $\sigma$ - морского желудя (Balanusimprovisus, Cirripedia)

Особенностью этих объектов является наличие раковины, в которую заключена гидратированная живая биологическая субстанция. Как видно, для обоих образцов характерно наличие области практически полной прозрачности в спектральном диапазоне 800-1350 нм. Значительное поглощение наблюдается в спектральных областях 200-745 и 1330-1800 нм. 
На рис. 4, $a$ и 4, $б$ приведены интегральные спектры поглощения внешней скелетной оболочки трубчатого червя (Polychaeta). Исследуемые образцы трубчатого червя Polychaeta имели сложную форму поверхности с областями различной окраски, что предполагает различные значения коэффициента поглощения. В связи с этим измерения коэффициента поглощения для каждого исследуемого образца проводились в нескольких точках при различных углах падения оптического излучения. Как видно, значительное поглощение излучения происходит, как и для приведенных выше случаев, в спектральных диапазонах менее 800 и более 1350 нм.
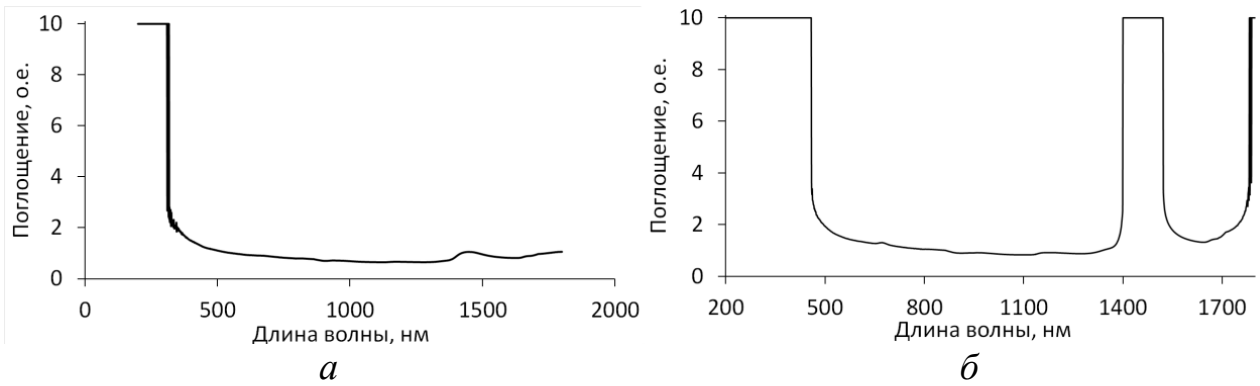

Рис. 4. Спектры поглощения для трубчатого червя Polychaeta: $a$ - спектр поглощения мягкими тканями; $\sigma$ - спектр поглощения внешней скелетной оболочкой

Таким образом, результаты экспериментального исследования процесса поглощения оптического излучения морской водой и наиболее характерными представителями отряда биообрастателей демонстрируют наличие значительного поглощения мягкими тканями организмов в спектральной области 200-700 нм, а также в области 1330-1800 нм, обусловленного поглощением морской воды, присутствующей в мягких тканях биообрастателей и особенностью их материала. При этом, как правило, наблюдаются области прозрачности в диапазонах 800-1350 нм.

\section{2. Спектры поглощения оптического излучения материалов, защищающих поверхности от биообрастания}

Регламентированные комплексные меры по защите подводной части корпусов морских судов от коррозии осуществляются нанесением лакокрасочных покрытий совместно с применением электрохимической защиты. Физико-химические и технологические свойства лакокрасочных материалов и способы их нанесения на подводные части 
корпуса морских судов установлены действующими российскими и международными нормативными документами [7].

В процессе проведения исследований выполнены измерения поглощения излучения в красках, используемых в качестве защитного покрытия корпусов подводной части судов. В качестве образцов использовались наиболее распространенные материалы: однокомпонентная акриловая краска марки INTERSPEED 6200, умеренно самополирующаяся противообрастающая краска Trilux 33 и грунт марки Sea Line GRPEPOXYLIGHTPRIMER, применяемый для нанесения на металлические поверхности подводной части корпусов морских объектов перед их окраской необрастающими красками.

Коэффициент поглощения материалов защитных покрытий определялся в спектральном диапазоне 200-1800 нм.

На рис. 5 представлен результат измерения спектра поглощаемых длин волн INTERSPEED 6200, Trilux 33 с добавкой FORAFLEX-X и грунта Sea Line GRPEPOXYLIGHTPRIMER.

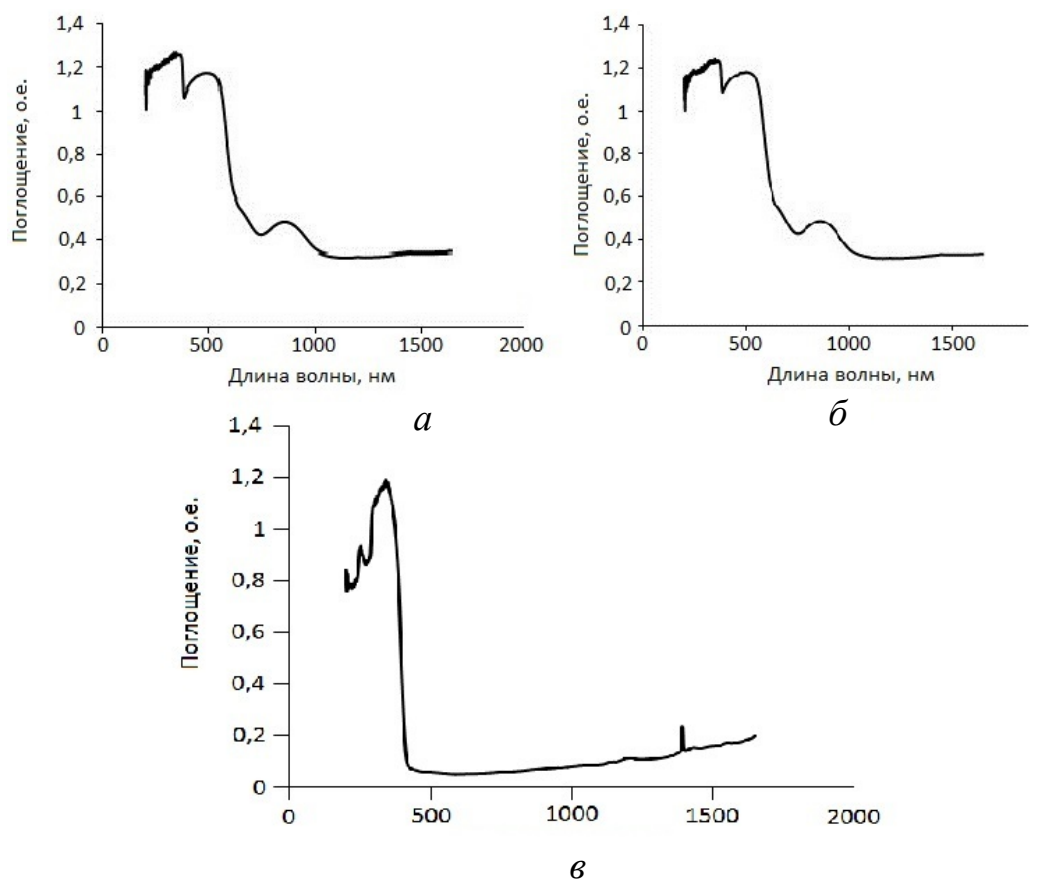

Рис. 5. Спектры поглощения для красок, используемых для защиты подводной части поверхности корпусов морских объектов: $a$ - спектр поглощения для краски марки INTERSPEED 6200; $\sigma$ - спектр поглощения для краски Trilux 33; в - спектр поглощения для грунта марки Sea Line GRPEPOXYLIGHTPRIMER 
В спектральной области 200-800 нм для INTERSPEED 6200 (см. pис. 5, a) и Trilux 33 (см. рис. 5, б) наблюдается значительное поглощение, в то время как для Sea Line GRPEPOXYLIGHTPRIMER (см. рис. 5, в) рост поглощательной способности регистрируется в диапазоне 200-400 нм. Анализируя измеренные значения коэффициентов поглощения исследуемых красок, можно отметить, что в диапазоне длин волн 1000-1800 нм спектры поглощения не имеют выраженных максимумов, а значения коэффициентов поглощения не превышают 0,4 о.е.

\section{3. Спектральное поглощение оптического излучения конструкционными материалами корпусов морских объектов}

Исследование спектров поглощения наиболее распространенных материалов корпусов судов выполнено на образцах из судостроительной стали категории $\mathrm{A} 32$ (основа $\mathrm{Fe}$ ) и деформируемого алюминиевого сплава категории 1530 (основа Al).

На рис. 6 представлены результаты измерения коэффициента поглощения в диапазоне длин волн 1000-1800 нм для конструкционных материалов корпусов судов.

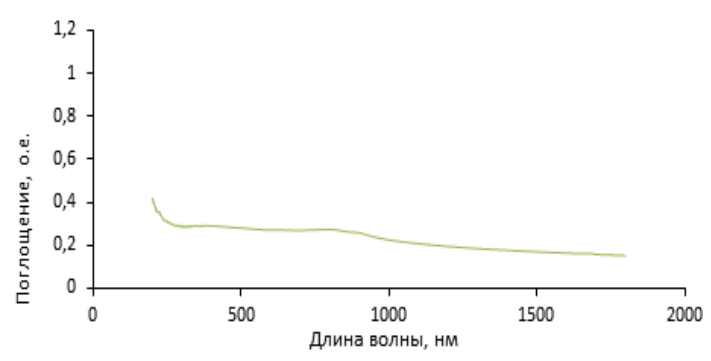

$a$

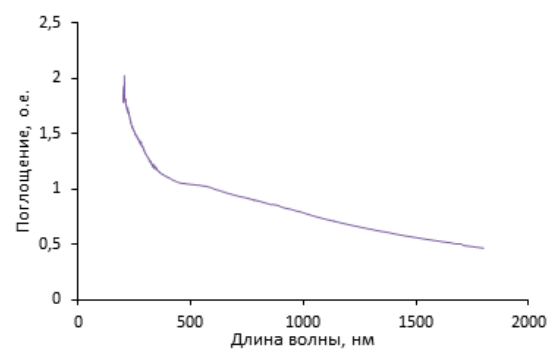

6

Рис. 6. Зависимость поглощения оптического излучения от длин волн для конструкционных материалов корпусов судов: $a$ - спектр поглощения для деформируемого алюминиевого сплава категории 1530; $\sigma$ - спектр поглощения для судостроительной стали категории А 32

Для сплава категории 1530 (см. рис. 6, a) коэффициент поглощения ЭМИ в диапазоне 200 - 1800 нм плавно увеличивается по мере уменьшения длины волны. Минимальное измеренное значение коэффициента поглощения наблюдается в инфракрасном диапазоне длин волн и составляет 0,152 о.е. При уменьшении длины волны в сторону ультра- 
фиолетового диапазона коэффициент поглощения достигает максимального измеренного значения 0,413 о.е. при длине волны 200 нм.

Рост поглощательной способности стали А32 (см. рис. 6, a) происходит более интенсивно по мере уменьшения длины волны. Максимальный коэффициент поглощения составляет 1,901 о.е. при длине волны $\lambda=200$ нм.

Результаты экспериментального исследования поглощения оптического излучения наиболее применяемыми конструкционными материалами корпусов морских объектов характеризуются плавным изменением зависимости поглощения оптического излучения от длин волн диапазона 200-1800 нм. В спектральной области 1000-1800 нм наблюдаются относительно небольшие изменения значений поглощения исследуемыми материалами.

\section{3. Принятие решения о выборе длины волны в системе лазерной очистки подводной части судов от морских организмов-обрастателей}

Интенсивность поглощения лазерного излучения при воздействии на поверхность твердого тела определяется коэффициентом поглощения, зависящим от множества факторов, в том числе от свойств материала и длины волны излучения [8].

Оптимальное решение по выбору длины волны лазерного излучения для задач подводной лазерной очистки принималось с учетом полученной релевантной информации о поглощательной способности морской воды, биоорганических материалов, красок и металлов.

На участке длин волн 1400-1500 нм морская вода имеет максимальную поглощательную способность (см. рис. 1).

Анализируя измеренные спектры поглощения оптического излучения основных представителей морских организмов, наиболее активно участвующих в процессах биообрастания, установлено, что в спектральном диапазоне 1400-1500 нм практически у всей исследуемой биоты наблюдается повышенное значение коэффициента поглощения $\alpha$.

Для сплавов, используемых для изготовления корпусов судов и лакокрасочных материалов, применяемых в качестве защитного покрытия этих корпусов, поглощение в диапазоне 1400-1500 нм имеет достаточно низкие значения (см. рис. 6). 
Проведенные исследования, направленные на решение задачи по созданию условий подводного взаимодействия лазерного излучения с биообъектами, находящимися во влажной среде, показали, что лазерный пучок должен находиться в «воздушном/газовом» пузыре. При этом процесс удаления биообрастателей с подводной части поверхности объектов должен выполняться сканирующим (равномерно перемещающимся) лазерным пучком достаточной интенсивности в непрерывном или импульсном режиме.

Таким образом, наиболее эффективным для подводной лазерной очистки поверхности морских объектов от влажных биообрастателей с минимизацией рисков возможного повреждения лакокрасочных материалов покрытий и металлического корпуса является излучение в спектральном диапазоне 1400-1500 нм.

\section{2. Метод и технология лазерной подводной очистки поверхностей от биообрастателей}

Техническое решение для создания условий взаимодействия лазерного излучения (ЛИ) с биообъектами, находящимися под водой, представлено на рис. 7. Разработанная конструкция щелевого сопла (см. рис. $7, a$ ) обеспечивает под водой создание воздушной области из сжатого воздуха давлением до 0,8 МПа.
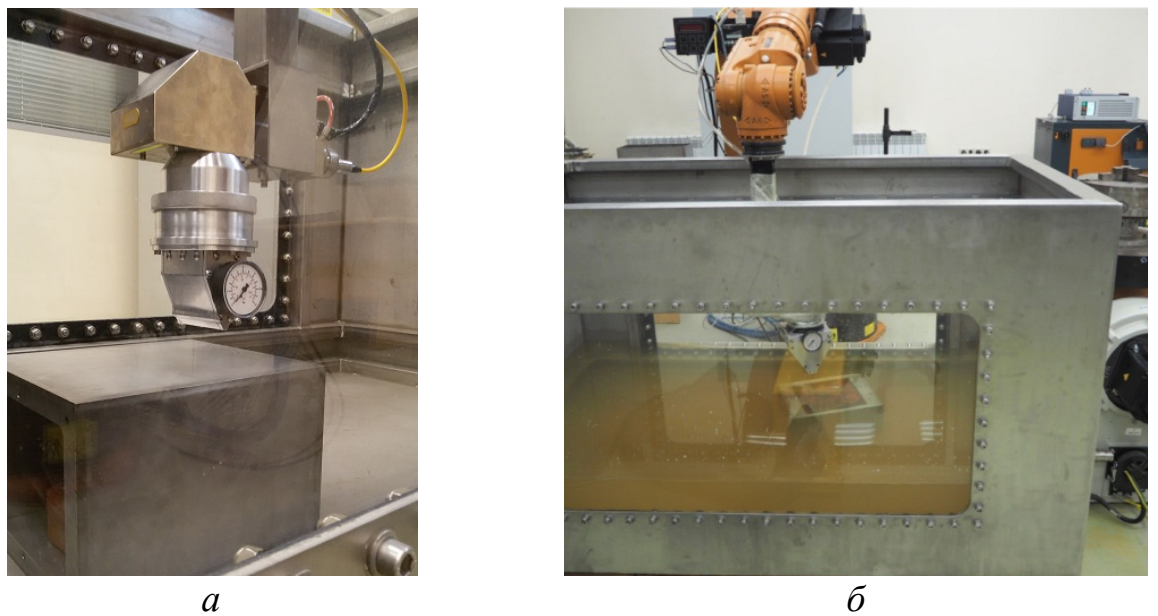

Рис. 7. Внешний вид макета щелевого сопла в комплекте со сканирующей лазерной головкой: $a$ - макетщелевого сопла; $\sigma$ - опытовый бассейн для проведения исследований процессов взаимодействия лазерного излучения с объектами, находящимися под водой 
Исследование процесса взаимодействия излучения $\mathrm{Yb}$-волоконных лазеров с биообъектами, образцами красок и материалов корпусов судов выполнялось в опытовом бассейне (см. рис. 7, б). На рис. 8 приведены фотографии, иллюстрирующие биообрастание стальных и стеклопластиковых пластин после двухмесячного пребывания в воде Японского моря. Результат лазерной подводной очистки этих пластин представлен на рис. 9.

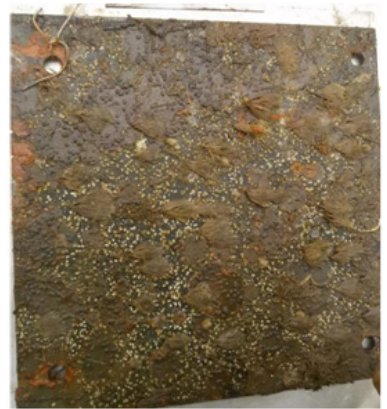

$a$

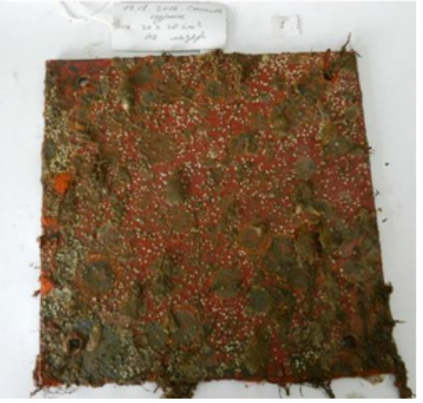

$\sigma$

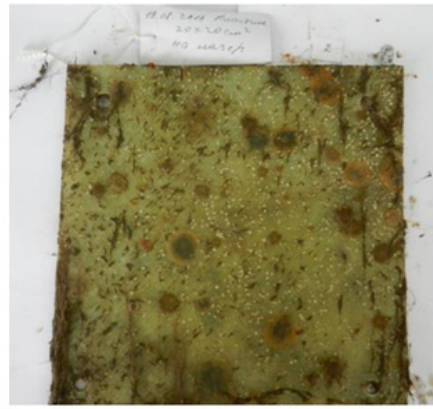

$B$

Рис. 8. Иллюстрация процесса биообрастания образцов после двухмесячного пребывания в морской среде: $a$ - образец из стальной неокрашенной пластины; $\sigma$ - образец окрашенной стальной пластины; в - образец пластины из стеклопластика

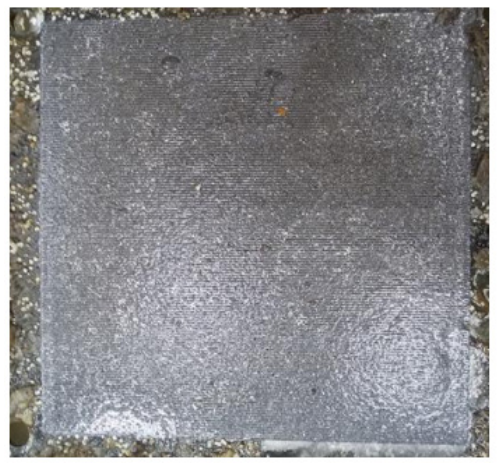

$a$

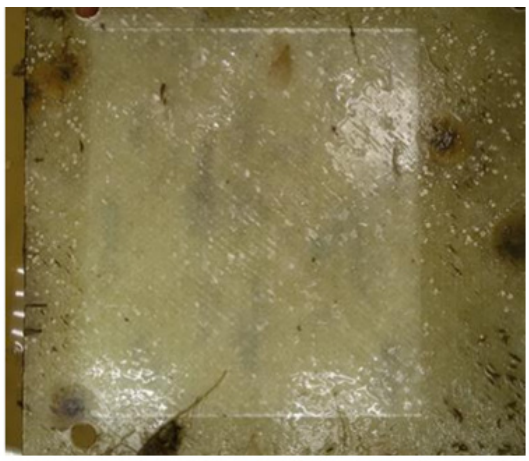

$\sigma$

Рис. 9. Фотография пластин после лазерной очистки: $a$ - образец из стальной неокрашенной пластины; $\sigma$ - образец пластины из стеклопластика

В конструкцию действующего макета роботизированного комплекса подводной лазерной очистки от биообрастания включены дополнительные элементы, обеспечивающие механическое водонепроницаемое сопряжение щелевого сопла с модулем очистки, входящим с состав обо- 
рудования подводного модуля. В схему защиты оптических компонентов сканирующей головки от влаги включен датчик воды, позволяющий осуществлять текущий контроль герметичности механических соединений элементов щелевого сопла. Внешний вид макета роботизированного комплекса подводной лазерной очистки представлен на рис. 10.

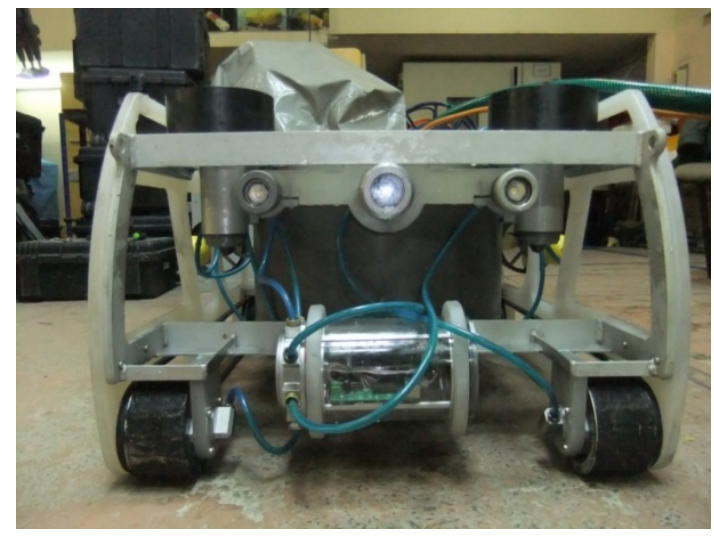

Рис. 10. Внешний вид макета роботизированного комплекса подводной лазерной очистки

Макет роботизированного лазерного комплекса (в составе телеуправляемого подводного робота и волоконного лазера) позволяет производить подводную очистку от биообрастателей корпусов судов, а также горизонтально и вертикально ориентированных технических и гидротехнических объектов со скоростью $15 \mathrm{~m}^{2} /$ ч на глубине до $10 \mathrm{~m}$. Разработанный комплекс оснащен системами видеонаблюдения, способными дистанционно контролировать качество очистки и состояние поверхности объекта.

Стендовые испытания макета аппарата лазерной подводной очистки поверхности объектов от биообрастателей в условиях воздействующих факторов, влияющих на функционирование разработанной конструкции, позволили провести углубленное исследование рабочего процесса лазерной подводной очистки. Полученная информация будет использована для разработки технических условий опытного образца роботизированного комплекса лазерной подводной очистки поверхности объектов от биообрастателей. На рис. 11 представлен процесс испытаний макета роботизированного комплекса подводной лазерной очистки. 


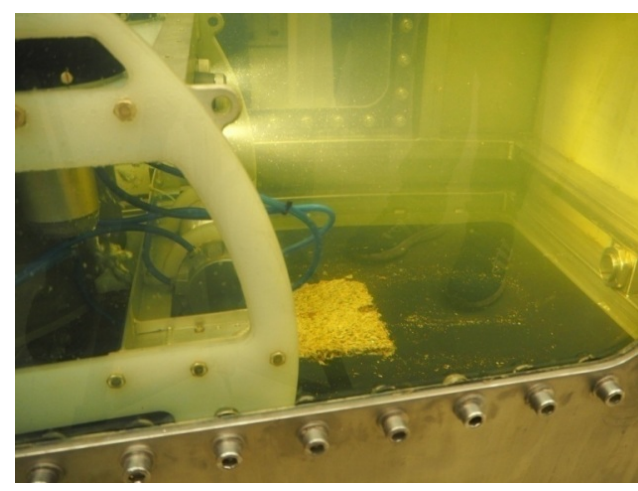

$a$

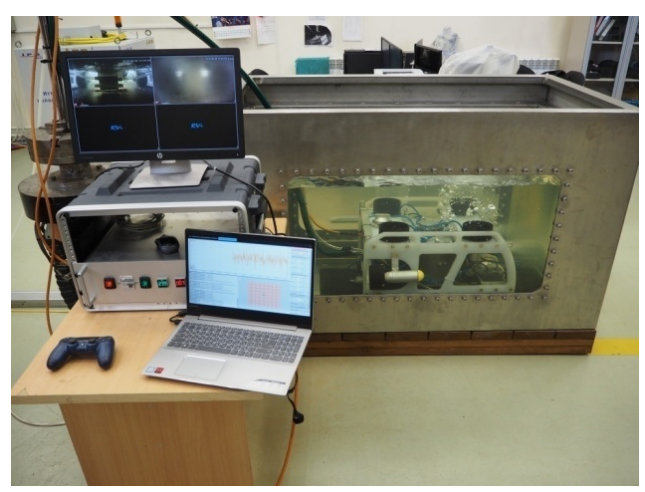

$\sigma$

Рис. 11. Стендовые испытания макета роботизированного комплекса подводной лазерной очистки: $a$ - процесс лазерной подводной очистки; $\sigma$ - система управления макетом комплекса лазерной подводной очистки

Результаты проведенных исследований показали, что для оптимизации скорости процесса подводной лазерной очистки целесообразно производить очистку от обрастателей с периодичностью 1-2 месяца. При такой длительности экспозиции объектов в морской среде наиболее трудно удаляемые с их поверхности кальциевые структуры биообрастателей только начинают формироваться. Поэтому лазерное излучение небольшой мощности 100-200 Вт обеспечивает полное их удаление, взрывая кальциевые домики за счет мгновенного вскипания находящейся внутри них жидкости. При этом обеспечивается удаление и всех других растительных наслоений, которые являются питательной средой для последующих организмов, и сохраняется лакокрасочное покрытие поверхности. При соответствующем выборе длины волны и энергетических параметров лазерного излучения очистку корпуса судна можно проводить без повреждения краски и металла со скоростью не менее $15 \mathrm{~m}^{2} /$ ч, при средней стоимости 0,25 долл./ $\mathrm{M}^{2}$.

\section{Заключение}

Созданный роботизированный комплекс лазерной очистки подводных поверхностей судов и морских сооружений позволяет удалять органическую пленку, формирующуюся на подводной поверхности корпуса судна в течение первых трех месяцев после докования, являющуюся основой питательной среды для последующих макрообрастателей, а также кальциевые пленки и первичные кальциевые отложения биологических объектов. 
Режимы лазерного излучения рассчитывались таким образом, чтобы исключить возможность повреждения защитного лакокрасочного покрытия и металла корпуса судна. Разработанные технические решения роботизированных комплексов могут обеспечить дистанционный контроль процессов лазерной очистки корпуса судна и его эксплуатационное состояние.

Поскольку после очистки морские организмы продолжают прикрепляться к поверхности корпуса судна, процедуру очистки следует периодически повторять. Для поддержания ходовых качеств судна, близких к заданным эксплуатационным, достаточно производить очистку судна 1 раз в 3 месяца.

\section{Список литературы}

1. Перспективы и технико-экономические аспекты разработки новых методов контроля биообрастания на морском транспорте / Ю.Н. Кульчин, А.Ю. Звягинцев, Е.П. Субботин, С.И. Масленников, А.А. Бегун // Вестник Дальневосточного отделения РАН. - 2015. - № 6.

2. Быканова А. Ю., Костенко В.В., Львов О.Ю., Никитин А.И., Субботин Е.П., Костянко А.А. Роботизированный комплекс подводного инспектирования и лазерной чистки судов на плаву // Технические проблемы освоения мирового океана: материалы Седьмой Всерос. науч.-техн. конф. / ФАНО России ФГУБН ИПМТ ДВО РАН. - Владивосток, 2017. - С. 122-128.

3. Отчет о научно-исследовательской работе в рамках Программы научных фундаментальных исследований Дальневосточного отделения РАН «Дальний Восток» на 2015-2017 гг. по проекту 15-I-7-021 «Управление процессом фоулинга поверхностей металлических и композиционных конструкций в морской среде лазерным излучением» (№ госрегистр. АААА-А16_116101710021-9). - Владивосток, 2018.

4. Подводная очистка, окраска и освидетельствование морских судов с использованием технических средств. Система подводной очистки, освидетельствования и окраски судов на плаву: отчет о науч.исслед. работе. Техническое предложение ГБТ-43/79 / Мин-во морского флота СССР; ДВВИМУ им. адмир. Г.И. Невельского. - М., 1983. - 133 с. (№ госрегистр. 80048111).

5. Разработка эталонов обрастания и качества подводной очистки транспортных судов: отчет о науч.-исслед. работе. ХДТ-20/83 / Мин-во 
морского флота СССР; ДВВИМУ им. адмир. Г.И. Невельского. - М., 1983. - 85 с. (№ госрегистр.01830064581).

6. Беликов А.В., Пушкарева А.Е., Скрипник А.В. Теоретические и экспериментальные основы лазерной абляции биоматериалов. - СПб.: Изд-во СПбГУ ИТМО, 2011. - 118 с.

7. Российский морской регистр судоходства. Правила классификации и постройки морских судов. - М., 2005. - Т. 2. - 640 с.

8. Григорьянц А.Г, Шиганов И.Н., Мисюров А.И. Технологические процессы лазерной обработки. - М.: Изд-во МГТУ им. Н.Э. Баумана, 2008. - 664 с.

\section{References}

1. Kul'chin Iu.N., Zviagintsev A.Iu., Subbotin E.P., Maslennikov C.I., Begun A.A. Perspektivy i tekhniko-ekonomicheskie aspekty razrabotki novykh metodov kontrolia bioobrastaniia na morskom transporte [Prospects and technical and economic aspects of the development of new methods for controlling biofouling in marine transport]. Vestnik Dal'nevostochnogo otdeleniia RAN, 2015, no. 6 .

2. Bykanova A. Iu., Kostenko V.V., L'vov O.Iu., Nikitin A.I., Subbotin E.P., Kostianko A.A. Robotizirovannyi kompleks podvodnogo inspektirovaniia i lazernoi chistki sudov na plavu [Robotic complex for underwater inspection and laser cleaning of ships afloat]. Tekhnicheskie problemy osvoeniia mirovogo okeana. Materialy Sed'moi Vserossiiskoi nauchno-tekhnicheskoi konferentsii. Vladivostok, 2017, pp. 122-128.

3. Otchet o nauchno-issledovatel'skoi rabote v ramkakh Programmy nauchnykh fundamental'nykh issledovanii Dal'nevostochnogo otdeleniia RAN “Dal'nii Vostok” na 2015-2017 gg. po proektu 15-I-7-021 “Upravlenie protsessom foulinga poverkhnostei metallicheskikh i kom-pozitsionnykh konstruktsii v morskoi srede lazernym izlucheniem” (№ gosregistratsii AAAA-A16_116101710021-9) [Report on research work within the framework of the Program of Scientific Basic Research of the Far Eastern Branch of the Russian Academy of Sciences "Far East" for 2015-2017. according to the project 15-I-7-021 "Control of the process of fouling of surfaces of metal and composite structures in a marine environment by laser radiation" (state registration number AAAA-A16_116101710021-9)].

4. Podvodnaia ochistka, okraska i osvidetel'stvovanie morskikh sudov s ispol'zovaniem tekhnicheskikh sredstv. Sistema podvodnoi ochistki, 
osvidetel'stvovaniia i okraski sudov na plavu: otchet o nauchno.issledovatel'skoi rabote. Tekhnicheskoe predlozhenie GBT-43/79 [Underwater cleaning, painting and survey of sea vessels using technical means. System of underwater cleaning, survey and painting of ships afloat: report on scientific research. work. Technical proposal GBT-43/79]. Ministerstvo morskogo flota SSSR; DVVIMU imeni admirala G.I. Nevel'skogo. Moscow, 1983, 133 p. (№ gosregistratsii 80048111).

5. Razrabotka etalonov obrastaniia i kachestva podvodnoi ochistki transportnykh sudov": otchet o nauchno-issledovatel'skoi rabote. KhDT-20/83 ["Development of standards for fouling and quality of underwater cleaning of transport vessels": report on research work. HDT-20/83]. Ministerstvo morskogo flota SSSR; DVVIMU imeni admirala G.I. Nevel'skogo. Moscow, 1983, 85 p. (№ gosregistratsii 01830064581).

6. Belikov A.V., Pushkareva A.E., Skripnik A.V. Teoreticheskie i eksperimental'nye osnovy lazernoi abliatsii biomaterialov [Theoretical and experimental foundations of laser ablation of biomaterials]. Saint Petersburg: SPbGU ITMO, 2011, 118 p.

7. Rossiiskii morskoi registr sudokhodstva. Pravila klassifikatsii i postroiki morskikh sudov [Russian Maritime Register of Shipping. Rules for the Classification and Construction of Sea-Going Ships]. Moscow, 2005, vol. 2, $640 \mathrm{p}$.

8. Grigor'iants A.G, Shiganov I.N., Misiurov A.I. Tekhnologicheskie protsessy lazernoi obrabotki [Technological processes of laser processing]. Moscow: Moskovskii gosudarstvennyi tekhnicheskii universitet imeni N.E. Baumana, 2008, 664 p.

Получено 17.11.2020 